\title{
Las representaciones sociales rurales de los "no-indios" ante el ocaso de la ciudad agraria colonial: los Andes centrales neogranadinos en la encrucijada borbónica
}

\author{
The rural social representations of the "non-Indians" in the face of \\ the decline of the colonial-agrarian city: the Central Andes of Nueva
}

Granada at the bourbon crossroads

Vladimir Montaña Mestizo*

Université de Tours, Francia

DOI: $10.22380 / 2539472 X .2001$

\begin{abstract}
RESUMEN
A fines del siglo XVIII las formas de representar socialmente a la población rural no indígena comenzaron a redefinirse en atención a si se provenía de lo conglomerado o de lo disperso. Durante el periodo de los Habsburgo, cuando el límite socioespacial fundamental estaba dado por lo conquistado y lo no conquistado, las colonias fueron asentamientos urbanos/rurales organizados y controlados alrededor de entidades político-administrativas más o menos conglomeradas; allí se era mestizo, español o indio, independientemente del lugar de residencia. No obstante, la promulgación de la Real Instrucción de 1754, la ampliación de la frontera interna y el giro fisiocrático, entre otros eventos, hicieron posible una ampliación de este mundo colonial. En este artículo muestro cómo esto implicó la desestructuración de las lógicas de ordenamiento y control social: como nunca antes, provenir de las ciudades o de las pequeñas aldeas o despoblados comenzó a ser factor de alteridad entre la población no indígena (vecinos, libres y mestizos).
\end{abstract}

Palabras clave: libres de todos los colores, vecino, mestizo, representación social, campo/ciudad.

\begin{abstract}
At the end of the eighteenth century, social representation processes of the non-indigenous rural population began to be resignified according to whether it came from conglomerate or dispersed spaces. During the Habsburg period, the fundamental socio-spatial boundary was given by the conquered and the unconquered, and the colonies were urban/rural settlements organized and controlled around more or less conglomerate political-administrative entities. There, one was mestizo, Spanish or Indian regardless of the place of residence. However, the promulgation of the Royal Instruction of 1754, the expansion of the internal frontier, and the physiocratic turn made possible the expansion of this colonial world. This expansion implied the destructuring of the rules of social order and control. In this article I show that, as never before, the fact that someone came from the cities, small villages, or uninhabited areas became a factor of otherness among the non-indigenous population (vecinos or neighbors, libres or free-people and mestizos).
\end{abstract}

Keywords: libres de todos los colores, vecino (neighbor), mestizo, social representation, country/city.

vladimir.montana.mestizo@gmail.com / https://orcid.org/0000-0001-8521-9471 


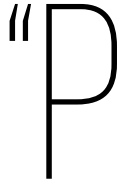

ara que el campesino cuente, tiene que ser contado”. Esta reivindicación, por medio de la cual los movimientos campesinos de hoy llaman la atención del Estado para ser considerados como sujeto colectivo de derechos, es un corolario que bien pudiera aplicarse a las gentes rurales neogranadinas del siglo XVIII. Hace más de dos siglos, la proliferación de libres de todos los colores, la diferenciación entre mestizos y mestizos limpios, y la funcionalización política de los vecinos notables de las aldeas mostraron las profundas transformaciones que estaba sufriendo el viejo régimen social colonial. Procesos migratorios, abandono de resguardos, extinción de pueblos de indios, juegos de interés, formas de residencia temporal e itinerante concordantes con los ciclos productivos de las emergentes haciendas y, por cuenta de todo ello, el desencadenamiento de diversas expresiones de transfiguración interétnica y mestizaje volvieron las categorías y representaciones sociales mucho más flexibles que en tiempos precedentes. En estas condiciones, el mundo social rural era incomprensible para el Estado colonial, cuyo control y legitimidad política habían estado fundados hasta entonces en el conteo de los indios y de sus tributos.

Durante el gobierno de los Habsburgo, las tierras efectivamente controladas se parecían a un archipiélago más o menos poblado, más o menos disperso, en medio de un mar de selvas y territorios baldíos (LeGrand 1988). La mayor parte de la cartografía colonial era entonces imaginaria y considerada tierras de realengo - es decir, lo que toca y pertenece al rey-, zonas aún no invadidas. Los asentamientos efectivamente controlados incluían por su parte lo agrario y civil, y cada entidad político-administrativa estaba dotada de unos terrenos de uso individual (solares, aposentos, peonías y caballerías) y otros de uso comunal (resguardos, ejidos, dehesas, propios, tierras del común, tierras concejiles) de vocación agrícola o pastoril. Estas unidades, que incluimos como referentes de la ciudad agraria, eran el fundamento de una vida colonial que, incluso en el sentido más castizo del término, tuvo dos acepciones complementarias, una agraria y otra civil, y que el mismo Diccionario de autoridades de 1729 bien pudo reconocer:

COLONIA. Población o término de tierra que se ha poblado de gente extrangera, trahida de la Ciudad Capital, o de otra parte. Los Romanos llamaban tambien assí a las que se poblaban de nuevo de sus antiguos moradores. Es voz puramente Latina Colonia. [...]

COLONO. El labrador que cultíva y labra alguna tierra por arrendamiento. Latín. Colonus, de donde viene. [...] (Real Academia Española 1729, 419-420) 
A partir de la segunda mitad del XVIII se generó un quiebre de esa ciudad civil y agraria constituida - en América - sobre un régimen de representación fundado en una noción escolástica de la raza. Allí un indio era un indio, independientemente de que viviera en la ciudad, morara en la periferia o se ocupara del cultivo del maíz en un lejano resguardo; lo mismo ocurría con un español o un mestizo.

Ello cambió con la progresiva reivindicación del trabajo agrícola que fomentó la fisiocracia y el renovado mercantilismo español. Diferentes propuestas y una serie de disposiciones fueron dando entonces una mayor particularidad a los territorios que estaban más allá de la cité colonial. Se promulgaron en consecuencia diversas disposiciones dirigidas a la desamortización (Nieto 2002) e individualización de la tierra: en la Península, mediante los repartos de baldíos de 1767, 1768, 1770, 1790 y 1793 (Pérez Picazo 2003) y, en América, principalmente, mediante la Real Instrucción de 1754, que a la postre buscaba dar valor al uso de la tierra sobre los títulos reales (Ots Capdequí 1959). A este mismo contexto se vinculan las expediciones botánicas de Ruiz y Pavón en Perú, de Sessé y Cervantes en Nueva España e incluso de Mutis en el Nuevo Reino de Granada y de Cuéllar en Filipinas. La inestabilidad de una economía exclusivamente ligada a la explotación y el tráfico de metales preciosos había hecho que el proyecto borbónico en América comenzara a pensar la propiedad y la producción agraria como la estrategia esencial de un nuevo orden social y económico. En las obras de José Campillo y Cossio y Bernardo Ward, ministros de Felipe V que propusieron tempranamente un nuevo sistema de gobierno económico para América, salta a la vista el interés por desarrollar políticas específicamente agrarias que, de modo progresivo, fueron separando institucionalmente el campo y la ciudad.

Los textos de los ministros Campomanes (Reflexiones sobre el comercio español a Indias, 1762) y Jovellanos (Expediente de la Ley Agraria, 1795) hablan de un agitado reformismo a los dos lados del Atlántico: mientras en América se reformaban los regímenes de las tierras de uso comunal, en la Península la lucha era principalmente contra la Mesta. En este contexto, los procesos de colonización y poblamiento se repotenciaron, aumentó la migración de españoles al continente americano ${ }^{1}$, se generaron nuevas e inéditas territorialidades que propiciaron una ampliación de la frontera agrícola, y se fomentaron con vigor la propiedad individual y los procesos de desamortización de las tierras de la

1 Este es un tópico que, luego de muchos años de negligencia investigativa, tuvo notables avances en las últimas décadas con el "descubrimiento" de América. Ver análisis de migraciones, para el País Vasco, en Ruiz de Azúa y Martínez de Ezquerecocha (1992); para Andalucía, en Díaz-Trechuelo (1991); para las Islas Canarias, en Macías Hernández (1994); para Galicia, en Eiras Roel y Rey Castelao (1992). Ver, además, Mörner (1991, 1995). 
Figura 1. Tabla de contenido del texto Nuevo sistema de gobierno económico para la América
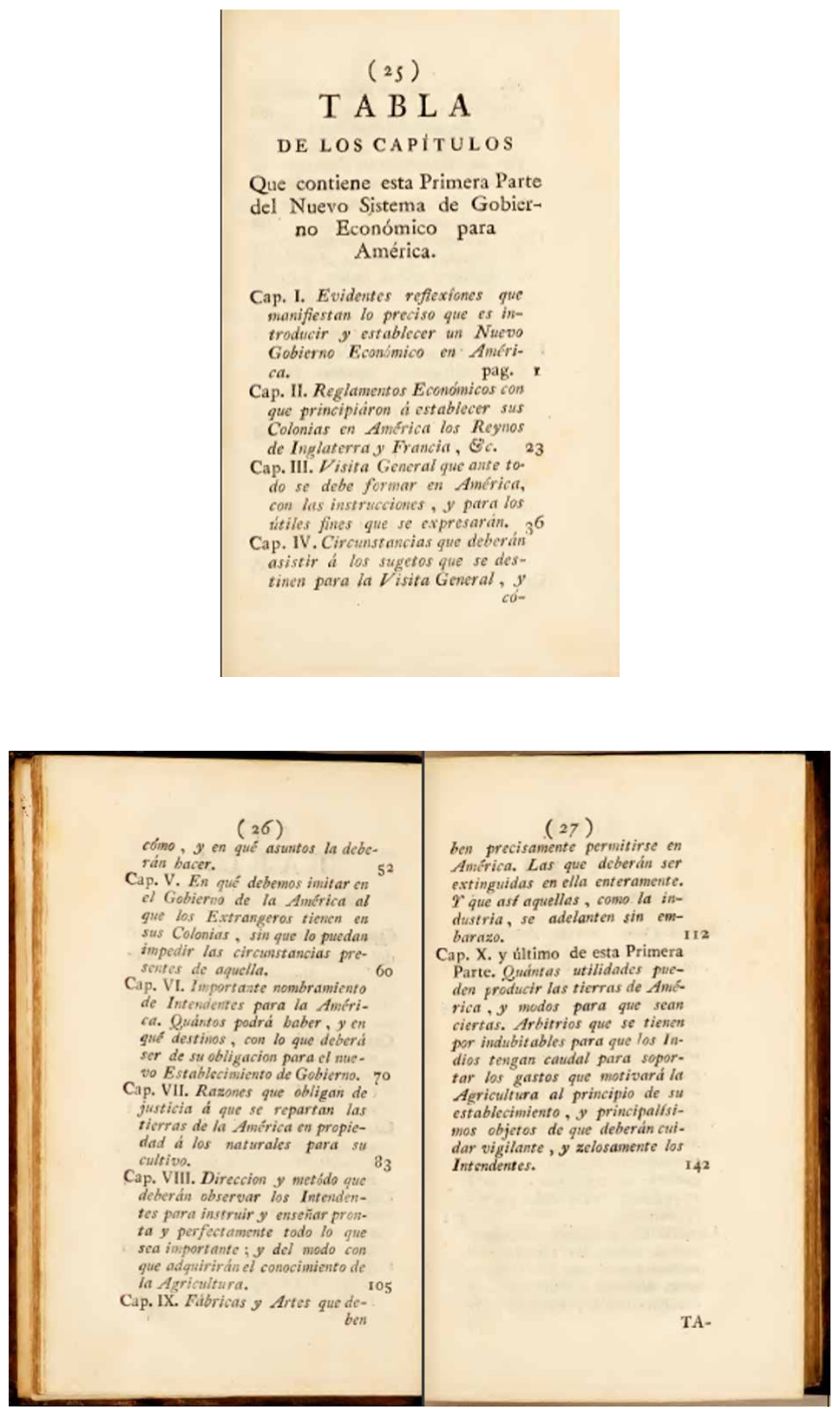

Fuente: Campillo y Cosío ([1743] 1789, 25-27). 
Iglesia. Sin embargo, en esta transición no se produjo la imposición de nuevas categorías de segmentación o reconocimiento social, tal como había ocurrido en el siglo XVI; el rezago de la gloria colonial y el mantenimiento mismo del patronato (legitimación papal de la ocupación española a cuenta de la evangelización) hicieron que las viejas categorías y representaciones sociales se continuaran usando - aunque con significados y funciones diferentes-. Estamos hablando de una lenta y compleja pero silenciosa reconfiguración del sentido de la alteridad colonial, así como de la emergencia de nuevas formas de reconocimiento y de exclusión social sobre las que quisiéramos profundizar.

La segunda mitad del siglo XVIII estuvo determinada por el ocaso de la ciudad agraria y la emergencia del límite campo-ciudad como referente de la representación social. Mostraremos que las estrategias del mundo borbónico por "ordenar y controlar" en medio de una explosión de diferentes tipos de colonización, así como de la más profunda crisis de las instituciones coloniales, coadyuvaron a que la diferencia campo/ciudad progresivamente se constituyera en un factor esencial de representación del Otro. Haciendo referencia al trabajo de Marta Herrera Ángel (2002), donde se reconoce el poder del control y del ordenamiento, nos permitiremos también contemplar la dimensión de lo no controla$d o$, de lo no ordenado, y de aquellos espacios y gentes que resultaban "ilegibles" para el Estado (Serje 1985). Al lado del ordenamiento y el reordenamiento están también el descontrol y lo desordenado, y ello no se puede omitir en el contexto de unas dinámicas de ampliación del espacio colonial, de colonización y de apropiación autárquica del territorio, por ser allí donde —en muy buena medida-se configuraron las nacientes sociedades rurales colombianas.

Al abordar la relación entre las dinámicas de poblamiento y ocupación del espacio y su confrontación (concordante y discordante) con las políticas borbónicas de ordenamiento territorial, analizaremos entonces las representaciones sociales rurales del mundo no indígena a fines del siglo XVIII. Este análisis se efectuará a partir de una escala temporal de larga duración, y si bien nos centraremos en la segunda mitad del siglo XVIII, nos permitiremos ampliar la escala hasta los siglos XVI y XIX; consideramos que solo esta variación focal nos permitirá observar las variaciones en cuanto a significado, uso y función de las mencionadas representaciones. En un primer momento, analizaremos la resignificación de la representación vecino, que comenzó a ser el referente principal de adscripción local y que otrora se usaba para referirse exclusivamente al colono "legítimamente" asentado. Seguidamente, analizaremos la representación mestizo, cuyo significado comenzó a tener usos y funciones políticas diferenciadas según se enunciara en ciudades, aldeas o pueblos sin burocracias locales, donde no era necesario poner a jugar el estigma de la mancha de sangre. Finalmente, 
analizaremos la representación libre de todos los colores, que evidencia un descontrol o la reconfiguración de un viejo régimen colonial de representación.

\section{La ciudad agraria de los Habsburgo}

Verdad es que tenemos la costumbre, como instintiva, de calificar de población rural aquella porción de labradores, que habita en los menores grupos de casas; pero ¿dónde está la regla, el criterio siquiera, de hasta

dónde llega, y de dónde no pasa esta clasificación? ¿Quién ha fijado el número de viviendas que distinguen la población rural de la que no lo es? ¿Dónde se encuentra disposición legislativa, ni opinión aceptable, que nos marque cuál pueblo es rural y cuál no? Caballero $(1863,12)$

La anterior referencia corresponde a un agrarista español que, encargado de diseñar un plan de fomento de lo que en esa época ya se conocía como población rural, encontró no pocas dificultades para definir ese concepto. ¿Cuál era esa población a la que debía dirigirse?

Todos los pueblos grandes y pequeños están en el campo, porque todos tienen una zona de ronda, afueras, ruedo, rastro y término cultivable, excesivamente mayor que el área de su casco. La corte misma cuenta su parte mínima de población agrícola, no siendo raro ver por sus alineadas calles de edificios, con cuatro y más pisos, los gañanes con las yuntas orgullosos del ruido que hace la rastra de sus arados sobre los adoquines [...] Por el contrario, en la más reducida aldea suele haber profesores, clérigos, chapuceros y otros vecinos no agrícolas, como hay casas aisladas de ermitaños, guardas y peones camineros, que tampoco se dedican al cultivo. (Caballero 1863, 11)

Las dificultades que encontraba Caballero para definir lo rural tenían que ver, entonces, con la indefinición de la ciudad española y, en general, de lo urbano:

En España, más que en otras naciones, ofrece gran dificultad la distinción, tanto por referirse a otras ideas los nombres genéricos de las poblaciones cuanto por la manera variadísima en que los moradores están distribuidos sobre el terreno. Ciudad, villa y aldea son voces, que no se contraen al número de habitantes, sino a sus antiguos privilegios. Madrid es villa y Huete ciudad; Zambra es aldea y Albarañez es villa. La población de las provincias peninsulares, a más de diferir mucho respecto de la superficie que ocupa, varía infinito en los grupos de edificios que constituye: mientras en las de Pontevedra, Barcelona y Guipuzcoa 
hay dos y tres mil habitantes por legua cuadrada, en las de Ciudad Real, Albacete y Cuenca solo existen de trescientas a cuatrocientas personas por legua; y cuando en la provincia de Oviedo se cuentan ochocientas quince parroquias y más de cinco mil poblaciones para medio millón de almas, en la de Cádiz no hay más de cuarenta y cuatro pueblos para cerca de cuatrocientos mil habitantes. En Galicia y Asturias se acercan a quince mil los lugares y aldeas de doce a cincuenta casas, y en Andalucía se llaman aldeas poblaciones de casi cuatrocientos vecinos.

Caballero $(1863,12)$

El problema que identifica Caballero para la España del siglo XIX tiene que ver con unos sistemas de territorialidades múltiples construidas en medio de diversos procesos de larga duración - fundamentados en una ruralidad amplia y diversa de una tradición visigoda-, así como con su concordancia con el derecho romano justinianeo, implícito en las Siete Partidas del gobierno del rey Alfonso X. Ello desde luego llegó a América. Tras la invasión española, los soldados de tropa, los peones de a pie, fueron concebidos inicialmente como los fundadores de una cultura agrícola colonial. La atribución de solares de labranza, lo mismo que de peonías y caballerías, sugiere que estos “peones” fueron los referentes de las primeras leyes de poblamiento y agrarización. Una disposición de Carlos $\mathrm{V}$ en 1523 señaló que los oficios de crianza y labranza debían ser obligatorios durante los primeros cuatro años de haber sido otorgados los amparos, gracias y/o mercedes de tierra (Solórzano y Pereira y León Pinelo [1647] 1774, 102 r.); una vez cumplido dicho término, la Ley Real daba potestad para que las mencionadas tierras pudieran ser vendidas. La Ordenanza 127 de Felipe II señaló más tarde que, una vez repartidas las tierras para ejidos, dehesas y propios comunes, lo mismo que para casas, solares, peonías y caballerías individuales, se debía velar por el establecimiento efectivo de sementeras y ganaderías. La Ordenanza 132, promulgada por el mismo monarca, instruyó que esto debía llevarse a cabo con anterioridad al levantamiento de casas y edificios. La Ordenanza 137 se refería a los colonos como pobladores (Ley XVI) y estableció específicamente la necesidad de encargar a una persona en particular del cuidado de las sementeras comunes:

que se ocupe en sembrar y cultivar tierra de pan y legumbres que luego se puedan recoger; y en la dehesa echen todo el ganado que llevaren y pudieren juntar con sus marcas y señales para que luego comience a criar y multiplicar. (93 v.)

Pero la constante ampliación del mundo colonial, el creciente interés de la tropa por obtener una riqueza y su enrolamiento en nuevas "conquistas” hicieron que la vida colonial y el establecimiento de colonias no fueran 
materializados en el cuerpo de los españoles. La presencia y la permanencia de españoles en las estancias, peonías y caballerías no fue fácil por dos razones: 1) no eran consentidas las ausencias prolongadas con destino a labranzas y cuidado de ganaderías porque generaban un desgobierno en aquellas tierras inhóspitas ${ }^{2}$; 2) mantener la gracia de las tierras recibidas de la Corona implicaba que los viejos soldados, además de todo, adquirieran compromisos difíciles de cumplir. Felipe II estableció, por ejemplo, que aquellos vecinos que hubieran aceptado hacerse cargo de peonías o caballerías estaban obligados a:

tener edificados los solares, pobladas las casas, hechas y repartidas las hojas de tierras de labor, y haverlas labrado, puesto de plantas, y poblado de ganados las que fueren de pasto, dentro de tiempo limitado, repartido por sus plazos, y declarado lo que en cada uno ha de estar hecho pena de que pierdan el repartimiento de solares, y tierras y más cierta cantidad de maravedies para la república. (102 v.)

En estas condiciones, como era de prever, los indios terminaron ocupándose de la agricultura. El abastecimiento de alimentos de las ciudades y villas no provenía entonces de un mundo "rural" bien conformado y delimitado territorialmente, sino de uno constituido por indígenas desperdigados en asentamientos dispersos de familias nucleares bajo el gobierno, principalmente, de corregidores y curas (Herrera Ángel 2002). Vale en este punto decir que solo muy tardíamente la fundación de haciendas coloniales, cuya vocación era inicialmente ganadera (Tovar Pinzón 1988), comenzaría a cumplir alguna función en la producción de alimentos. Esta especialización de los indígenas como agricultores, junto con el uso de su fuerza de trabajo en mitas (urbanas y rurales), generó un sistema de asentamientos que resulta ininteligible a la moderna lógica campo/ciudad; se vivía, pues, en haciendas, minerales, reales de minas, asientos de minas, aduanas, ventas, puertos, islas, presidios, caseríos, rancheríos, anejos, doctrinas, cortijos y rancherías, “donde hay en cada parte diferentes Casas esparcidas a lo largo de los Ríos, Quebradas y Minerales” (Pando 1770, citado en Herrera Ángel 2001, 84). torizaciones eran posibles "siempre y cuando [las ausencias] fuesen breves" (95 v.). 


\title{
Del privilegio a la constricción: la resignificación de los vecinos
}

\begin{abstract}
Significa también la razón de vecino en un Pueblo, por la habitación, un domicilio en el tiempo determinado por la ley [...] Significa asimismo cercanía, ó proximidad de una cosa à otra. Dícese especialmente de las casas, ó quartos de habitación... Metaphoricamente se usa por cercanía ú proximidad en qualquier línea [...] Asi mismo metaphoricamente se toma por semejanza, ó coincidencia en las cosas inmateriales.
\end{abstract}

Real Academia Española (1739, 428 r.)

El significado de la palabra vecino ejemplifica la complejidad, la diversidad y las transformaciones en la denominación de aquellos "colonos" que decidieron llevar sus vidas en tierras más o menos distantes de los centros político-administrativos coloniales. En los primeros tiempos del periodo colonial, vecino era la palabra con la que se distinguía a un poblador legalmente asentado en cuanto colono. Un vecino era un colono de todo derecho. Cualquier nueva población debía tener no menos de diez vecinos y sus parientes y, en muchas de ellas, el primer vecino era el encomendero; así por lo menos lo deja ver la Ley V del 23 de agosto de 1538 (Solórzano y Pereira y León Pinelo [1647] 1774, 88 v.). Cada nueva fundación, según el rango de la capitulación que le preveía, tenía un mínimo y un máximo de vecinos autorizados a instalarse y a vivir bajo el amparo real. Las ordenanzas 88 y 89 de Felipe II dejan ver que los vecinos constituían una especie de "unidad de medida" de las nuevas fundaciones; de su número y "calidad" dependía el establecimiento de ciudades, villas o lugares (88 v.). Según el Diccionario de autoridades, un vecindario era la "lista, nómina u matrícula de vecinos que se arregla para algún repartimiento” y, conforme a esta idea, definía vecino como aquel individuo que "tiene casa, hogar en un pueblo, y contribuye en las cargas u repartimientos” (Real Academia Española 1739, 420).

La legitimidad del vecino como habitante legal implicaba el cumplimiento de diferentes deberes: sufragar los sacramentos y demás derechos parroquiales, contribuir a la llamada fábrica de iglesia (mejoras, ornamentos, cofradías), y pagar corrientemente diezmos y primicias. Estas “inversiones” no eran redimibles solamente en el campo de lo espiritual; más allá, tenían implicaciones sobre el ordenamiento político local. Tamar Herzog (2003), en un estudio que aborda desde la vieja Castilla hasta el siglo XVIII latinoamericano, muestra que el vecino es ancestro del ciudadano y una representación fundamentalmente civil. Ello explica su relación con la noción de raizalidad que, naturalmente, toma mucha 
más fuerza en contextos de colonización y movilidad residencial. En estas circunstancias, advertimos tres usos de la representación vecino: 1) diferenciaba y distinguía a los indios tributarios ${ }^{3}$; 2) diferenciaba y distinguía a los libres de todos los colores; y 3) diferenciaba y distinguía el estatus social de los mestizos.

Inicialmente no hubo unos parámetros generales del vecinazgo, razón por la cual fueron las comunidades las que usualmente regularon los derechos y deberes del ser vecino según fueros y costumbres propias (Herzog 2003). En el siglo XV parece haber comenzado una cierta homogeneización de los derechos: un vecino podía montar a caballo, portar armas, acceder a las tierras y a los pastos de uso comunal, y ser elector y elegido en cargos del cabildo (Ordenanzas de Ávila 1487). De otro lado, para ser aceptado como tal, se requería la aprobación de los vecinos asentados (Ordenanzas de Jaén 1553) y haber vivido en la localidad durante al menos diez años. Nada indica, o por lo menos no en la recopilación de Solórzano y Pereira y León Pinelo ([1647] 1774), que tales parámetros hayan cambiado en América.

Con el tiempo, la adscripción de un individuo o familia a un vecindario no dependía del ser raizal o de la cercanía a la doctrina; para los más ricos era posible elegir su lugar de vecindad. Si se trataba de pobres, el asunto se resolvía entre los curas, como ocurrió en el pueblo de indios de Gachancipá (1727-1734), cuando el cura-vicario recomendó que los indios fuesen integrados al curato (de indios) del pueblo de Nemocón, al otro lado del río, para facilitarles cumplir con la doctrina (AGN, Poblaciones-Var, sc. 46, leg. 8, doc. 11). La representación de un vecino tenía por demás variables diversas. Si el padrón de vecinos se levantaba en una villa de blancos, podría incluir sirvientes, indios, libres, mestizos, solteras, solteros, pardos y/o esclavos; ello queda claro para el caso de Pamplona en 1793 (AGN, Miscelánea, sc. 39, leg. 43, doc. 13) o Monguí (AGN, Miscelánea, sc. 39, leg. 44, doc. 41). No obstante, si el padrón de vecinos era levantado en pueblos de indios, como en el caso de Cómbita (AGN, Visitas-Boy, sc. 62, leg. 13, doc. 16) y Tibasosa (AGN, Miscelánea, sc. 39, leg. 41, doc. 26), tal representación era abiertamente excluyente de la población indígena.

Con el aumento y poblamiento de las áreas rurales, la definición de vecino fue objeto de reconfiguración. El factor raza tenía poca pertinencia cuando lo que se jugaba en las pequeñas aldeas era el deber de contribuir, en cuanto vecinos, con las obras públicas, el diezmo, las cofradías (de españoles) y demás obligaciones reservadas para la población no indígena. El reconocimiento del

3 Caso curioso es la consulta que se efectuara en Cacota de Velasco (Norte de Santander), incluso en 1831 (AGN, Indios, sr. 52, leg. 1, doc. 200), a propósito de la eventual alcaldía de un indígena ante la ausencia de vecinos blancos. 
vecino era desde luego la puerta de entrada a ciertos privilegios - como gracias y mercedes de tierra - o cargos políticos de importancia local, como alcalde, alguacil o fiscal (Bayle 1950). También se visibilizaría en la subrepresentación vecinos notables, cuya alusión es reiterativa en los documentos del siglo XVIII, principalmente, y que refiere a las dinámicas de segmentación microsocial del mundo colonial no indígena. Empero, el pago de los estipendios para algunos vecindarios no era tan fácil de llevar a cabo y muchas veces la Corona tuvo que asumirlo, como ocurrió en el "sitio" de Morales, cerca de Cartagena (AGN, Miscelánea, sc. 39, leg. 63, doc. 26, f. 446 r.). Ser vecino en algunos casos implicaba de hecho pagar unas contribuciones que quizás era mejor evitar, incluidos los estipendios de la doctrina, diezmos y demás; en ese sentido, para muchos vecinos potenciales pudo ser en ocasiones mucho más deseable verse representados como libres de todos los colores.

La ilegalidad de la presencia de foráneos en los pueblos de indios (Mörner 1963) y las consecuencias que ello acarreaba de manera permanente hicieron que, en muchos casos, la vecindad resultara más una carga que un privilegio. Un expediente de 1744 referente al sitio de Morales (provincia de Cartagena) muestra por ejemplo que, como resultado de las sucesivas expulsiones, los vecinos se tornaron migrantes sin control político (AGN, Miscelánea, sc. 39, leg. 140, doc. 58, f. 565 v.) . $^{4}$

La transformación del significado del vecino llegó, sin embargo, con los procesos de extinción de pueblos de indios y la erección de parroquias de blancos a partir de la segunda mitad del siglo XVIII. Estas reformas tuvieron un origen fundamentalmente económico. A esas alturas, en el Nuevo Reino los tributos apenas lograban tasarse en "camisetas, alpargatas, mantas, lienzos y cobijones que no se podían vender ni aun en la tercera parte de su valor” (Verdugo y Oquendo [1754] 1963, 155-156). Verdugo y Oquendo (163) consideraba que las personas blancas podrían en efecto generar mayores ingresos a través del pago de primicias, diezmos y alcabalas (impuesto al comercio) que por concepto de requintos (de indios). El negocio borbónico era, pues, aumentar las rentas y disminuir el gasto de las doctrinas. En 1777 Campuzano y Sanz explicaba que, por ejemplo, el erario se liberó de las cargas de los extintos pueblos de Chevas, Burbanza, Tovaria y Turaza a expensas de la extinción de los pueblos de Tarco, Serinza, Sativa, Unzaga y Beteytiva (AGN, Visitas-Boy, sc. 62, leg. 16, doc. 16, ff. 979 v.-980 r.). Para Moreno y Escandón ([1775-1776] 1985), no era justo "pagar

4 La "fuga" llevada a cabo por los vecinos de San Luis en la parroquia de Santo Tomás como forma de negarse a ser trasladados a Baranoa, en 1745, y en particular el celo que manifestaron para conservar las campanas y alhajas del templo, muestra las profundas implicaciones que pudo tener para la población un traslado de vecindario (AGN, Poblaciones-Var, sc. 46, leg. 4, doc. 7). 
estipendio a un doctrinero por solo diez o veinte tributarios” (74). Esto se verifica también en el proceso de extinción del pueblo de San Francisco de la Montaña (en Veraguas) en 1805: "parece convendría el que inmediatamente pase a servir su beneficio, con lo que se evitará la Real Hacienda mucho gravamen” (AGN, Miscelánea, sc. 39, leg. 27, doc. 18, f. 554 v.).

El mantenimiento de las doctrinas era, desde luego, de alto costo para un Estado en quiebra, y es por ello que "según el crecido número de vecinos que cada pueblo tenía en su agregación podría establecerse en parroquia y mantener cura propio” (Moreno y Escandón [1775-1776] 1985, 69). El Estado colonial no podía rechazar entonces ofertas como las del vecindario de Carcasi (Santander, en límites con Casanare) en el periodo 1789-1807, que manifestaba asumir la responsabilidad económica del estipendio y administración de los sacramentos de indios y blancos, avaluado por los curas doctrineros en 50000 maravedíes (AGN, Poblaciones, sc. 46, f. 948 r.). Lo mismo ocurrió en La Palma en 1806 (AGN, Caciques e Indios, leg. 25, doc. 69). Pedro Fermín Vargas ([1789] 1944), por su parte, señalaba:

sería muy de desear que se extinguiesen los indios, confundiéndolos con los blancos, declarándolos libres de tributo y demás cargas propias suyas, y dándoles tierras en propiedad. La codicia de sus heredades haría que muchos blancos y mestizos se casasen con las indias y, al contrario, con lo que dentro de poquísimo tiempo no habría terreno que no estuviese cultivado en lugar que ahora la mayor parte de los que pertenecen a indios se hallan en eriales. (99)

Las consecuencias de estas reformas fueron sociales y culturales. Su implementación implicó convertir en vecinos a los libres de todos colores que vivían al margen del Estado, lo cual generó una reacción contraria entre ciertos grupos sociales:

hubo muchos opuestos en los curas, en los vecinos, y en los mismos indios, siempre opuestos a su bien; y que nunca podrán arreglarse mientras no se reduzcan a la clase de libres del tributo personal, como los demás, y sujetos a sus cargas. (Silvestre [1789] 1950, 100-101)

Y es que, al tiempo que se afectaban las lógicas microsociales de cada localidad, el proceso de homogeneización de los no indios afectaba instituciones que, como el clero regular, rentaban a partir del mantenimiento de los pueblos de indios. Para los dominicos, en particular, no era rentable la erección de parroquias y la pérdida de unos emolumentos que ahora se destinarían al clero secular. En su análisis de la separación entre el pueblo de indios de Belén de Cerinza y la parroquia de Santa Rosa —distantes una hora-, Verdugo y Oquendo ([1754] 1963) 
remarcaba un debate entre la población local azuzado por el cura doctrinero, un regular dominico. El nuevo alcance de la noción de vecino, compelido tras las dinámicas de extinción de pueblos de indios y la consecuente conformación de parroquias, llevó a que ciertos sectores sociales reivindicaran los viejos significados. La erección de una parroquia de vecinos implicaba privar a los regulares de sustraerles los réditos que normalmente percibían por cuenta de la doctrina. Verdugo y Oquendo ([1754] 1963, 184) recoge dicha problemática al recuperar una cédula real de 1750:

De que yo me dignase a expedir una orden general para que, ya estén encargados a Doctrineros Regulares, a sacerdotes regulares, se dividan en distintas parroquias sin mezcla alguna de los unos con los otros; y que hecha la división según reglas de mi Real Patronato, se ponga con la mayor prontitud y sin excusa ni pretexto alguno, curas clérigos en la parroquia respectiva.

En este punto, el significado también comenzó a variar según si dicha representación se enunciaba en pequeñas aldeas o, por el contrario, en ciudades y villas más tradicionales. En efecto, una cosa era ser vecino y reclamarse como descendiente de los primeros vecinos y otra, ser vecino de un rancherío en crecimiento. Ello tenía que ver, por supuesto, con el tamaño del Estado y con la posibilidad de enrolarse en la función pública. Mientras en las ciudades los vecinos podían aspirar a cargos burocráticos, eclesiásticos o militares, en las pequeñas villas y pueblos apenas podrían "gozar” —relativamente- de la exención tributaria. Las gentes de las pequeñas aldeas entendían las ventajas y desventajas (los usos y funciones) no solo de tal o cual representación, sino también de ser vecino bajo las condiciones de una u otra localidad. Esto se observa en el censo de 1777 (Gutiérrez de Pineda y Pineda Giraldo 1999, 129), en el que se muestra la proporcionalidad demográfica de la población indígena con respecto a los diferentes vecindarios y queda clara la existencia de unos factores que hicieron más atractiva la vecindad en ciertas localidades (Chita, Sogamoso o Santa Rosa de Viterbo).

No conviene, empero, homologar la representación social y política del vecino con la representación racial blanco. Incluso, tampoco conviene su homologación con el referente mestizo que, en las ciudades, había abandonado su relacionamiento con los factores religiosos y había adoptado rasgos claramente biopolíticos (Castro-Gómez 2005). Fue entonces cuando se comenzó a dibujar una diferencia entre los vecinos de las grandes ciudades y el vecino parroquiano de las pequeñas aldeas y villas. El análisis del censo de José María Campuzano y Sanz permite ver que vecinos y mestizos eran representaciones excluyentes: o se era vecino o se era mestizo - a menos de que se tratase de un propiamente mestizo 
Figura 2. Censo comparativo de indios y vecinos en algunas localidades de la cordillera Oriental

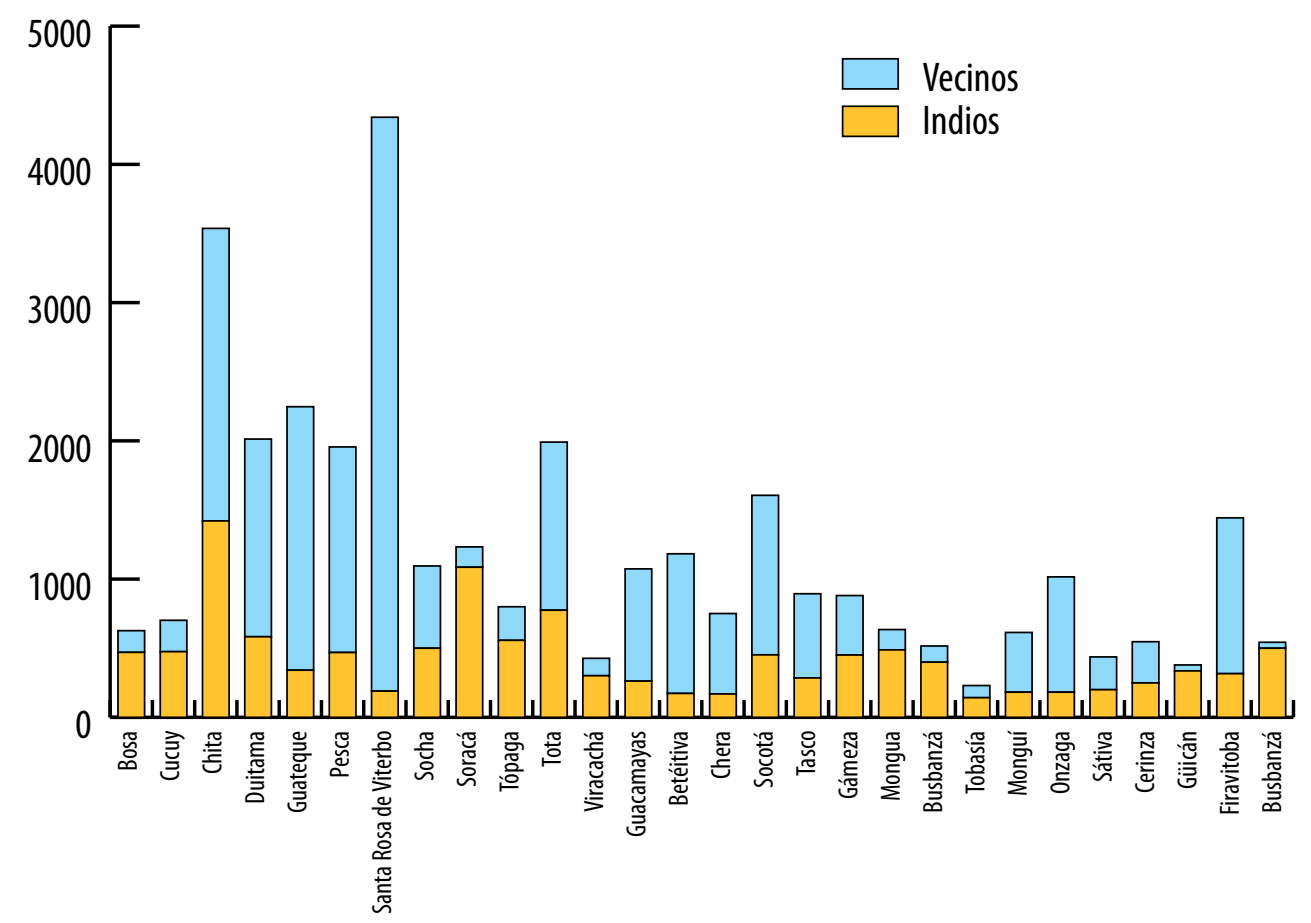

Fuente: elaboración propia con base en Gutiérrez de Pineda y Pineda Giraldo (1999, 129).

(o un mestizo limpio)—. Las razones tienen que ver más con la práctica social concreta que con las convenciones discursivas o ideológicas. El matrimonio de vecinos con indios y, en mayor medida, con indias - quienes en las sociedades matrilineales transmitían la herencia, filiación y sucesión- podría anular los derechos de uso del resguardo; a contrapelo, los hijos de un matrimonio india/ vecino - por cuenta de filiaciones matrilineales_- podrían beneficiarse del uso de tierras del resguardo e incluso acceder a otros "privilegios" derivados de la filiación y la sucesión indígena. Así, por ejemplo, un documento de 1795 muestra que en Gachetá se intentó obligar a pagar requinto a unos vecinos por el hecho de estar casados con indias (AGN, Tributos, sc. 60, leg. 16, doc. 20). En todo caso, la doble condición indio/vecino no parece haber sido admitida. 
Figura 3. Tipología de mestizos presentes en visita de Campuzano y Sanz

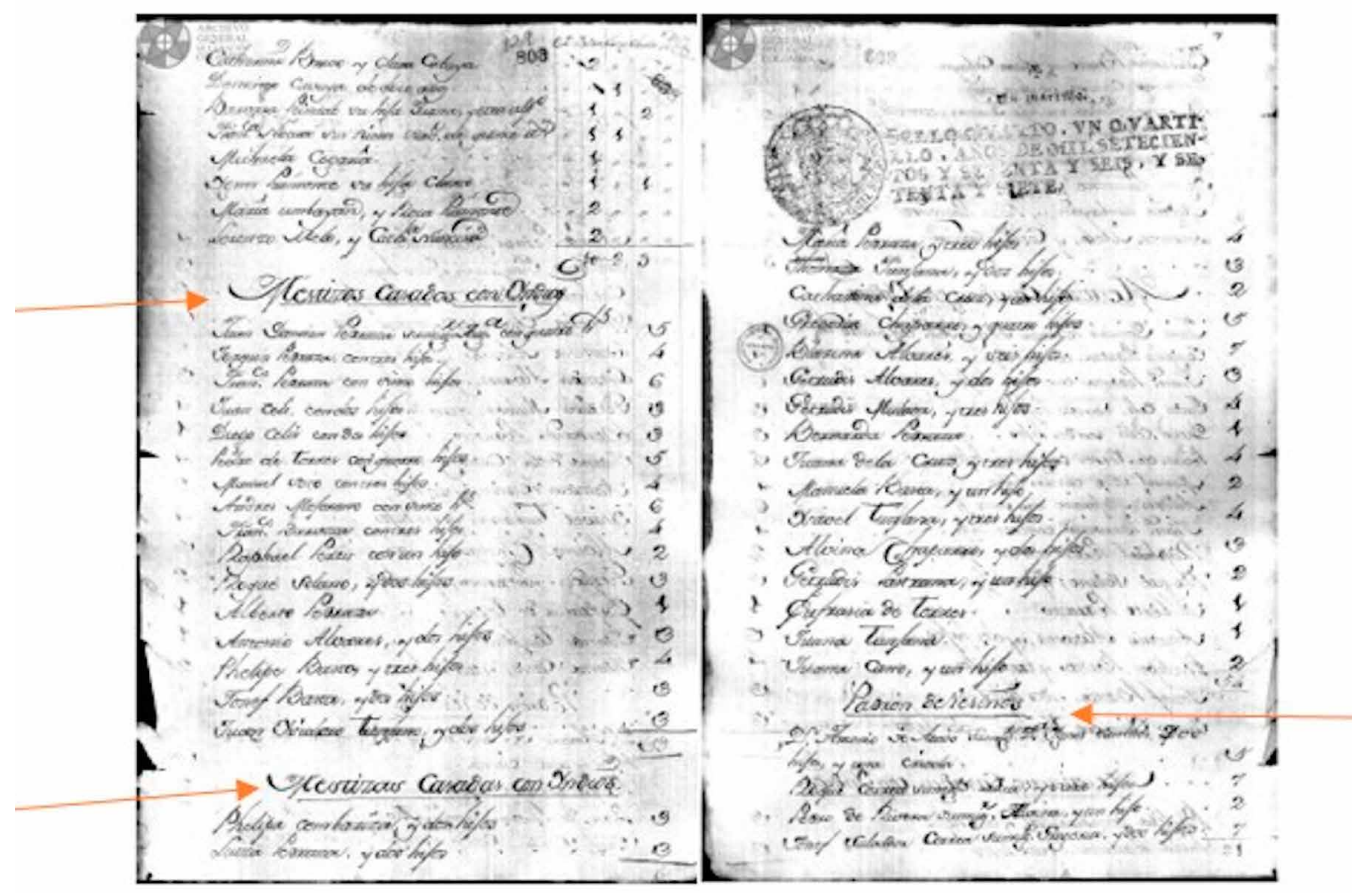

Fuente: imagen del documento original consultado en AGN, Visitas-Bol, sc. 62, leg. 5, doc. 7, ff. 829 r. y v.

\section{Libres de todos los colores, o la representación del desgobierno rural}

La representación libre de todos los colores, quizás la más significativa e inexplorada de los tiempos del reformismo borbónico, es confundida con la representación mestizo. Por ejemplo, hablando de los datos de Francisco Silvestre, Jaramillo Uribe $(1965,25)$ escribe que en el virreinato había 368093 libres, que en "el lenguaje de la época quería decir mestizos”. Pero es necesario hacer una claridad: el uso y la función de la representación libre no eran de tipo racial, sino político y fiscal. Se usó frecuentemente para diferenciar y clasificar aquellos actores sociales a quienes las viejas categorías coloniales (español, indio, mestizo, esclavo, vecino, etc.) no lograban sintetizar. El sector llamado libres de todos los colores incluía a todas aquellas gentes que, por razones diversas (procesos judiciales, 
asentamientos distantes, migraciones, fugas o mestizajes), no tenían definido un lugar dentro del orden social colonial; no avecindaban ni a pueblo ni a resguardo. Eran "montaraces”, “crimonosos” y “forajidos”: “escapados de la sociedad, por vivir sin ley ni religión” (Caballero y Góngora, en Colmenares 1989, 410-411).

Bastaría delinear un abreviado mapa de la población del Reino para que se conociera la confusión y desorden con que viven estos montaraces hombres, eligiendo a su árbitro y sin intervención del gobierno, no de los jueces subalternos el lugar de su retiro, tanto más agradable para ellos cuanto más apartado de la iglesia de su pueblo [...] esto nace de la arraigada libertad de huirse los unos de los otros para poder vivir a sus anchas y sin recelo de ser notados en sus infames y viles procedimientos [...] forman la mayor parte de los habitantes domésticos, hacen propiamente una población vaga y flotante, que obligados a la litaría de los propietarios, transmigran con la facilidad que les conceden el poco peso de sus muebles, la corta pérdida de su rancho y el ningún amor a la pila en que fueron bautizados. (Caballero y Góngora, en Colmenares 1989, 410-411)

Se trataba de unos nuevos salvajes, alejados de la civilización y de la religión. La denominación libres de todos los colores definía a personas que no eran clasificables, no eran controladas y constituían un ámbito social ajeno a los valores culturales del mundo borbónico; es por ello que su reducción - que significaba poblamiento- resultaba tan necesaria como lo muestran las políticas de poblamiento y fundación de nuevas parroquias a finales del XIX (Mörner 1970; Ots Capdequí 1952) ${ }^{5}$. Y es que los libres no tenían función alguna en ciudades y villas: de un lado, los tributos se pagaban en los pueblos de indios -que eran aldeas dispersas-y, de otro, en dichos centros urbanos las castas cumplían el papel de criterios de clasificación específicos para garantizar justamente el funcionamiento de la sociedad de castas (Dueñas Vargas 1997; Rodríguez 1997). En el mundo rural, la representación libres de todos los colores se refería a aquellos que no eran tributarios -incluyendo, de alguna manera, a los indios huidos, los colonos que no pagaban diezmo y los esclavos libertos-. Mientras tanto, en el mundo urbano, era una forma de denominar el lugar de lo indeterminado, es decir, de aquello que no cumplía ninguna función en el ámbito de una taxonomía biopolítica tan definida, en donde había "tercerones”, "cuarterones” o gentes tenidas como "tente en el aire” u otras representaciones que determinaban un lugar específico de mestizaje dentro de la biopolítica colonial.

5 Dicha lectura de los "habitantes de lo despoblado" se mantendría hasta el siglo XIX, cuando se propuso incluso que se les concediera - sin perjuicio- el derecho a la ignorancia de la ley. En el proyecto de código civil de 1853 de la Nueva Granada se estableció que este beneficio podría aplicar: "1. A los labradores que viven en despoblado; 2. A los pastores que viven errantes o en despoblado" (Congreso de la Nueva Granada 1853, 3). 
Cabe recordar que estas categorías no eran azarosas ni eran una simple transfiguración de la taxonomía característica de la Ilustración, sino que cumplían la función de reglamentar el acceso al aparato burocrático del mundo urbano colonial. Recordemos igualmente que los múltiples procesos de disenso social por causa del estigma de la sangre - o la mancha de la tierra-, pero así mismo las dinámicas de ascenso social por cuenta de un blanqueamiento nada fortuito, pudieron darse y tuvieron sentido en un mundo urbano exclusivamente. En los contextos rurales, por el contrario, estas representaciones no tenían uso o función semejante; no era necesario entonces comprar el blanqueamiento -llamado "gracias al sacar" - cuando se pertenecía al indistinguible cuerpo social de los libres de todos los colores, cuya trazabilidad filial —o sus ascendencias - era realmente imposible.

Al estar por fuera del control del Estado, los libres de todos los colores constituyen quizás el sector social menos estudiado de la historia colonial colombiana. Tal condición es comprensible si asumimos que esta expresión representaba lo opuesto al vecino, cuyo vínculo con la institucionalidad era estrecho. Según muestra Margarita Garrido (2007), ser referido como libre implicaba no obedecer ni reconocer autoridad alguna, pero también significaba no tener ninguna posibilidad de ejercerla. A finales del siglo XVIII, esta población era mayoritaria, por lo menos en algunos partidos donde el término libre tenía que ver con algún referente a la ilegalidad civil. Muchos eran indios y mulatos huidos, y es quizás por esta razón que suele confundírselos con los mestizos. Y es que, progresivamente, los indios comenzaron a liberarse de las cargas que los atormentaban (trabajos forzados, tributos, estigmatización); la fuga fue, como lo muestra Colmenares (1992), el método más usual de desindigenización. Eximirse de los listados de tributarios implicaba salir de sus resguardos sin dejar pista o huella alguna de su paradero, una vía que llevaba a la desindigenización. La movilidad residencial se oponía claramente a una noción colonial de raza que implicaba el confinamiento, ya fuera para el pago de tributos, como ocurría en los contextos rurales, o para los trabajos forzados de otros tipos de población.

La población "libre" era entonces conformada por colonos ilegales (de todos los colores) que no necesariamente eran reconocidos como vecinos, y que no pagaban los requintos y demoras, diezmos, primicias, alcabalas o cofradías, pero que tampoco estaban subordinados a los sistemas de gobierno propios de la república de indios. Describiendo el “estado de abominación” en que se encontraba el Nuevo Reino de Granada, el fraile Finestrad ([1789] 2001) señala:

Con efecto, ¿qué puede ofrecer la vida solitaria en unas criaturas ignorantes, penetradas de un condenable idiotismo, sin más principios de las máximas cristianas, ni más noticia de la religión que un gentil (per- 
mítaseme la expresión), que un idólatra? ¿En unas criaturas sin freno, con total libertad, mal domadas, sin educación, con la crasa ignorancia de la virtud, de la mortificación de las pasiones y la contención de apetitos, hirviendo la sangre en sus venas sin temor a Dios, ni a la iglesia, ni a la real justicia, qué puede emprenderse? Ellas viven en los montes y sus honduras, distantes de sus respectivas parroquias quienes, a un día entero de camino, quienes a distancia de medio día y muchos tres o cuatro horas. (123-124)

La libertad de los libres de todos los colores no era, empero, una libertad institucional y legal que, de tenerla, les habría otorgado el estatus de vecinos. Se trataba de una libertad obtenida por haber fijado residencia en tierras distantes de todo control institucional; abriendo la selva, ellos difícilmente tenían contacto con el control moral o político. Eran criminales morales en delitos tales como el amancebamiento o los matrimonios libres e intercastales. Finestrad ([1789] 2001, 123-124) señalaba que, por su modo de vida, cuando los padres salían al trabajo dejaban a sus hijas solas "en tales retiros", lo que facilitaba que ellas no guardaran "recato alguno en las licencias del matrimonio"; luego añadiría que en esa vida "solitaria” no era posible verificar si las gentes vivían "en carne o fuera de ella por estar separada de la sociedad tan prevenida, expuesta a los mayores desbarros y a las más tristes consecuencias”. Para Moreno y Escandón ([1775-1776] 1985), ellos vivían "separados de la sociedad”, se hallaban retirados de la Iglesia y sin asistir a misa, por lo que quedaban en "manifiesto peligro de su salud eterna, así como por la facilidad de incurrir en los excesos a que vive expuesta la naturaleza, sin temor de ser conocidos o corregidos, [y] por la grave dificultad de ser socorridos en última hora” (73).

\section{El mestizo urbano y el mestizo rural}

Ya hablamos de los mestizos puros, como son los de la primera clase, esto es, hijos de india y español, de los que bajan de condición como son los salta atrás y tente en el aire. He aludido a los primeros, y ahora digo de los segundos que en gran parte gozan de los privilegios de los españoles. No pagan tributo, no son destinados a trabajos públicos sin su consentimien-

to. Queda ahora por ver cuál es su condición ante el derecho eclesiástico americano. Por el parentesco de sangre que tienen con los indios, ya sean mestizos nuevos, ya sean de muchos años, son siempre tenidos por neófitos y gozan de los privilegios que les han concedido los Sumos Pontífices, privi- 
legios de los cuales no deben participar los cuarterones, ochavones y puchuelos, excluidos de ese rango por el Papa Clemente XI y agregados al de los blancos.

Mestizo constituye un atributo episódico, contingente y susceptible al cambio histórico. A través de su idea de “evanescimiento del sujeto mestizo”, Rappaport (2018) propone que: 1) no se era necesariamente representado como mestizo durante toda la vida; 2) no existía propiamente un “campo sociológico” del mestizo; 3) lo mestizo era una "perturbación” (nonplacement) y representar a un individuo implicaba un "ninguno de los anteriores" (17). Estas ideas, que cuestionan el valor explicativo del mestizaje como fenómeno estrictamente racial, biogenético e incluso fenotípico, permiten abordar la idea que venimos trabajando: la diferenciación de los mestizos urbanos y de los mestizos campesinos. Corrían pues tiempos en que las sirvientas urbanas eran llamadas "mestizas con hábito de india”, tal como lo muestra en detalle Rappaport (2018), y en los que el hecho de que un indio se cortara - o le cortaran- el pelo daba lugar a representarle como mestizo (Spalding 1974, 181-182).

Al final del periodo colonial, cuando la transformación y la mezcla dejaban de verse como una expresión tergiversada y corrupta de la perfecta obra de Dios, y cuando el "fijismo" dejaba de ser el marco de referencia de la historia natural (Rostand [1958] 1995), la noción de lo híbrido comenzó a tener nuevas y diversas implicaciones éticas. Ello impactó de igual forma a los vecindarios dispersos y a las pequeñas aldeas, en comparación con la influencia que el transformismo tuvo en los contextos urbanos. El siglo XVIII no era ese mundo colonial donde lucharon sujetos como Diego de Torres (el cacique Turmequé) o Alonso de Silva (cacique mestizo cuyo rango causaba resquemor por cuenta de su doble filiación y privilegio), sino uno en el que el medio social y político operativizó tal representación como dispositivo diverso de movilidad social, ya fuera por disenso - como ocurría en las ciudades-o por ascenso - como ocurría en los contextos urbanos-.

La aplicación de las representaciones sociales propiamente urbanas a la taxonomía emergente no tenía entonces que ver solamente con una transfiguración de la cultura europea, sino con una funcionalización concreta. Y es que, en las ciudades, la discriminación por mestizaje fue uno de los factores trascendentales en la estructuración social. Los mestizos no eran ningún tipo de clase media, sino el factor trascendental para torpedear la carrera de quien pretendiera ser español de sangre "limpia”. Para ello era importante la clasificación y a ello hacía referencia la biopolítica. La mera suposición de una "mancha en la 
sangre” que infería desmerecimiento llevaba a que en las ciudades se adelantaran investigaciones genealógicas que, a la sazón, resultaban más frecuentes y detalladas en cuanto más importante política y administrativamente fuesen la localidad y la familia en cuestión. Analizados en detalle para el caso colombiano por historiadores como Dueñas Vargas (1997) y Rodríguez (1997), el principio de la pureza española —o ausencia de mestizaje- resultó ser el fundamento de la clasificación y segmentación social y, por tanto, de la configuración de la clase alta colonial.

Lo contrario ocurría en las pequeñas villas, pueblos de indios y despoblados coloniales donde los archivos eran insuficientes o poco fiables. Allí, los pretendidos juicios de disenso social no tenían mayor factibilidad o, en caso de darse, no llegaban a ser lo suficientemente técnicos según los parámetros de la época. Ello implicaba que la categoría mestizo, como representación social, tuviese usos, funciones y reapropiaciones diferentes en las sociedades locales. La representación de alguien como mestizo en un contexto cuya filiación no fuera archivada o resultara precariamente archivada (Montaña Mestizo 2003) daba lugar a que individuos concretos fueran puestos a la merced de profesionales de la representación local (Bourdieu 1984), generalmente influidos por juegos de interés que excedían toda norma o acuerdo social. Este fue el caso de unos vecinos de Río Seco (corregimiento de Honda) que, sin haber sido nunca - ni ellos ni sus ancestros - tenidos como tributarios, resultaron así representados por cuenta de los conflictos de interés del corregidor del partido y del alcalde del pueblo, quienes tenían la costumbre de amenazar a los vecinos con hacerles pagar tributo; así le ocurrió a un vecino llamado Linares, "por haber comprado este unas tierras que sin título poseía dicho alcalde provincial” (AGN, Tributos, sc. 60, leg. 17, doc. 29, f. 729 v.). De este peculiar e inédito documento que analicé en otro lugar (Montaña Mestizo 2021) salta a la vista la aplicación de normativas que relacionan el mestizaje con los tributos y que, desde luego, no son observables en los contextos urbanos. Entre estas, por ejemplo, está la necesaria representación como tributario de un mestizo que fuese adoptado por un padre indígena: "Y todo hijo de Yndia soltera o casada con cualquier persona tributan sin repugnancia” (AGN, Tributos, sc. 60, leg. 17, doc. 29, f. 719 r.).

La relación entre el mestizaje y la operación historiográfica que había en las ciudades, y que estaba parcial o completamente ausente en los contextos rurales, tiene también explicación en las relaciones de parentesco local y en las posibilidades de establecer amplias relaciones de afinidad con parientes no consanguíneos. La regulación matrimonial dictada por el Concilio de Trento que justificaba en primera instancia la existencia de los archivos- era de muy difícil cumplimiento allí donde había fundamentalmente parentelas locales 
endógamas con muy poca posibilidad de cumplir las normas de filiación y grados de consanguinidad autorizados. El archivo, pues, allí no tenía mucha función cuando se trataba de los delitos más leves de cópula ilícita que sintetizaban las relaciones sociales en disidencia con Trento. Los archivos parroquiales de las pequeñas aldeas, a diferencia de lo que muestran los archivos de las ciudades, estaban entonces lejos de reportar los ascendentes hasta una tercera línea bilateral. Durante los bautismos, matrimonios y defunciones en pueblos y aldeas de las emergentes ruralidades, apenas se anotaban —en el mejor de los casos- los nombres y apellidos de los padres y consortes, lo que no les permitía convertirse en pruebas de consanguinidad en juicios de disenso o gracias al sacar. Emprender, por tanto, investigaciones genealógicas, llamamiento a testigos y todas las diligencias que caracterizaron a los juicios urbanos de disenso constituía misiones que al parecer no tenían mucho sentido y que, en todo caso, solo podrían ser sufragadas por familias poderosas y adineradas.

En tales circunstancias, eran muchos los escollos que encontraría alguien que quisiera llevar a cabo una pesquisa genealógica o efectuar una comprobación de pureza de sangre. El problema se complejizaba en aquellas regiones donde la movilidad residencial - primero indígena y luego de los libres - era una práctica vigente. Para el caso del altiplano central colombiano, Correa Rubio (2004) ha mostrado que la residencia indígena era inicialmente avunculocal —se moraba donde el tío, hermano de la madre-y la herencia era matrilineal, todo lo cual supone una amplia movilización en el territorio durante las diferentes etapas de la vida. A contrapelo, la movilidad residencial del emergente mundo agrícola requería normalmente de peones y cosecheros temporales, lo que deja suponer que llevar a cabo un ejercicio de investigación genealógica jamás fue sencillo, barato o generalizado.

Atendiendo a los aportes de Jacques Poloni-Simard (1999) en su aproximación al mestizaje urbano, en el que supone la existencia de unos "indios de ciudad”, queremos sobre todo exaltar la existencia de unos mestizos de campo, una representación social con uso y función muy diferentes a los que se les atribuían en las ciudades. Pigmentocracia, biopolítica y sociedad de castas han sido expresiones usuales para referir un régimen de representación muy documentado —fundamentalmente urbano- que, sin embargo, muy difícilmente pudo haber surgido en los emergentes contextos rurales. Representaciones tales como salto atrás, cuarterón, tente en el aire, etc. no tenían de hecho mucha operatividad en aldeas y despoblados, contextos de reducida migración y, por ello, con limitadas relaciones interculturales; por demás, los cargos de poder político y burocrático que podrían lograrse a través de la pretendida pureza de sangre eran exiguos. En las ciudades, la biopolítica colonial tenía sentido por ser allí donde se jugaban 
los privilegios dados a los españoles; no ocurría lo mismo, por lo menos no de la misma manera, en los contextos rurales.

Las dificultades para estudiar la representación mestizo en los contextos rurales pasa por los procesos de archivo documental. Vale decir que las gentes que requerían evitar verse - o querían ver a otros - alrededor de una mancha de sangre estaban generalmente avecindadas en las urbes principales y que, en los emergentes contextos rurales, el único disenso social posible - aunque ello no es poco importante- era el ser representado en cuanto tributario. En el mundo rural del siglo XVIII, la representación de alguien como mestizo era fundamentalmente un logro que podría eximir del odioso tributo; es por ello que en los archivos se cuentan a granel disposiciones del siguiente tenor:

Pedro Ordoñez, Joseph Ordoñez y otro Pedro Ordoñez, hijos de Fran[cisc]o Ordoñez sobre ser amparados en traer espada como esemptos de pagar tributos por ser hijos mestizos y haver servido a su Mag[esta]d sus padres y tíos. (AGN, Caciques e Indios, sc. 66, doc. 24, f. 696)

Finalmente, vale la pena remarcar la existencia de una profunda relación entre la representación del mestizo y la refuncionalización de las relaciones de parentesco que implicaba el desmembramiento social de las sociedades indígenas. No hablamos solamente de la familia extensa, sino también de la familia nuclear. En este punto es necesario atender lo sugerido por Fisher y O’Hara (2009) cuando discuten qué tanto las prácticas de representación social están influenciadas por las circunstancias de la vida privada. La diversidad de los procesos de mestizaje, en lo cual ha insistido Charles Hale (1996), no obedecería solamente a factores estructurales y a circunstancias que hacen prevalecer unas formas de mestizaje sobre otras (De la Cadena 2006), sino también al desarrollo de decisiones e instrumentalizaciones ejercidas en el ámbito de lo privado.

Se tiene entonces que, en tanto las representaciones de parentesco variaban entre el campo y la ciudad, los efectos de tal circunstancia - el mestizaje, por ejemplo - también lo hacían. Mientras mestizos de ciudad habrían perdido el vínculo social y político con las comunidades indígenas de sus ascendientes -que ciertamente no eran urbanas-, en los pequeños pueblos y aldeas un sujeto tenido como mestizo continuaba en efecto perteneciendo a una unidad de parentesco; por esta razón, podría - y debía - cumplir con las diferentes obligaciones (trabajo servil, tributo, concierto, etc.) que las tradiciones y su familia le demandaban. Estos mestizos, según usos y costumbres, podrían incluso acceder a ciertos derechos de herencia, filiación y sucesión indígena, como ya se mencionó. Ello, además, tenía implicaciones de género: así pues, en la medida en que el varón —en comunidades matrilineales— no transmite la filiación, fue usual que 
muchos hijos de madre indígena continuaran siendo considerados indígenas, pagando tributo y "disfrutando" del uso comunal de las tierras del resguardo. Un mestizo rural, entonces, engranaba los sistemas de parentesco del colonizador y del colonizado, resignificaba el lugar de las diferencias de género y, por tal motivo, más que delimitar "razas” en un sentido moderno, permitía la superposición de unos sistemas disímiles y asimétricos de cohesión social.

\section{Reflexiones finales}

La porosidad del espacio social colonial, las políticas públicas de ordenamiento y las dinámicas de significación y funcionalización del otro deben observarse, como hemos querido demostrar, en conjunto y de manera interrelacionada al momento de abordar el cambio social. Intentar comprender una representación social rural, tal como lo hicimos con las voces mestizo, libre y vecino, requiere necesariamente ir más allá del significado mismo de esas palabras —o de las transformaciones de esos significados- para entender su relación con los significados de ese espacio al que hoy llamamos "rural” o "campos”. Hemos querido mostrar que, en el pasado, ese espacio recibió acepciones diferentes que dieron sentido a las emergentes políticas públicas de control del territorio. Si bien el proyecto colonial se basaba en unos principios de ordenamiento y control territorial, vale también decir que paralelamente operaron dinámicas autárquicas de poblamiento que además influyeron en la reconfiguración de los modos de significar al otro. Una vez pasaban el control de la misa dominical o el ejercicio anual de la cofradía, las gentes rurales no indígenas tenían lógicas propias de relacionarse, de verse, de diferenciarse, de distinguirse y de clasificarse. Y es justamente frente a esas lógicas que luchaban -y luchan-las políticas de ordenamiento territorial.

Diferenciar, distinguir y clasificar al otro no solamente tiene que ver con imposiciones de significado. Al contrario, está íntimamente relacionado con el territorio vivido, con las cartografías imaginarias o con los planes y proyectos de "buena vida" que ambicionaban gentes de carne y hueso. Fue en medio de este cruce de factores donde se jugaron las transformaciones semánticas que refuncionalizaron y dieron nuevos usos a palabras tales como mestizo, libre y vecino. Esta es, pues, la antesala que nos permitirá ver las complejidades de las representaciones sociales rurales que ya se asomaban en el mundo poscolonial, y que cada vez ganaban especificidad en cuanto al control del tiempo y del espacio del 
mundo social arrendatario, aparcero, peón, labrador, gañán y luego, finalmente, campesino.

\title{
Referencias
}

\section{Fuentes primarias}

\author{
Archivos consultados
}

Archivo General de la Nación, Colombia (AGN). Fondos Caciques e Indios, Indios, Miscelánea, Poblaciones (Poblaciones-Var), Tributos, Visitas (Visitas-Bol, Visitas-Boy).

\section{Impresos}

Caballero, Fermín. 1863. Fomento de la población rural en España. Madrid: Imprenta de Aguado.

Campillo y Cosío, José del. (1743) 1789. Nuevo sistema de gobierno económico para la América. Madrid: Imprenta de Benito Cano.

Congreso de la Nueva Granada. 1853. "Proyecto de Código Civil”. https://catalogoenlinea. bibliotecanacional.gov.co/client/es_ES/search/asset/193040/0

Finestrad, Joaquín de. (1789) 2001. El vasallo instruido en el Estado del Nuevo Reino de Granada. Bogotá: Universidad Nacional de Colombia.

Gilij, Felipe Salvatore. (1782) 1955. Ensayo de historia americana: o sea historia natural, civil y sacra de los reinos, y de las provincias de tierra firme en la América meridional. Vol. 1. Bogotá: Editorial Sucre.

Moreno y Escandón, Francisco Antonio. (1775-1776) 1985. "Relación de la visita de Moreno, Dic. 1775-enero 1776”. En Indios y mestizos de la Nueva Granada a finales del siglo XVIII, introducción e índices de Jorge Orlando Melo, transcripción de Germán Colmenares y Alonso Valencia, 68-81. Bogotá: Fondo de Promoción de la Cultura del Banco Popular.

Real Academia Española. 1729. Diccionario de autoridades. T. 2. Madrid: Imprenta de Francisco Hierro.

—.1739. Diccionario de autoridades. T. 6. Madrid: Imprenta de Francisco Hierro.

Silvestre, Francisco. (1789) 1950. La descripción del Reyno de Bogotá. Bogotá: Biblioteca Popular de Cultura Colombiana.

Solórzano y Pereira, Juan y Antonio de León Pinelo. (1647) 1774. Recopilación de leyes de los reinos de las Indias. Vol. 2. Madrid: Antonio Pérez de Soto. 
Vargas, Pedro Fermín. (1789) 1944. Pensamientos políticos y memoria sobre la población del Nuevo Reino de Granada. Bogotá: Biblioteca Popular de Cultura Colombiana.

Verdugo y Oquendo, Andrés. (1754) 1963. “Informe del visitador Andrés Verdugo y Oquendo sobre el estado social y económico de la población indígena, blanca y mestiza de las provincias de Tunja y Vélez a mediados del siglo XVIII". Anuario Colombiano de Historia Social y de la Cultura 1: 131-196. https://revistas.unal.edu.co/index.php/achsc/article/view/29627

\section{Fuentes secundarias}

Bayle, Constantino. 1950. Los cabildos seculares en la América Española. Madrid: Sapientia.

Bourdieu, Pierre. 1984. “Espace social et genèse des 'classes”'. Actes de la Recherche en Sciences Sociales 52-53: 3-14. https://doi.org/10.3406/arss.1984.3327

Castro-Gómez, Santiago. 2005. La hybris del punto cero: ciencia, raza e ilustración en la Nueva Granada (1750-1816). Bogotá: Editorial Pontificia Universidad Javeriana.

Colmenares, Germán, comp. 1989. Relaciones e informes de los gobernantes de la Nueva Granada. Vol 1. Bogotá: Biblioteca Banco Popular.

- 1992. "La hacienda en la Sierra Norte del Ecuador: fundamentos económicos y sociales de una diferenciación nacional (1800-1870)". Revista Ecuatoriana de Historia 2: 5-49. http:// hdl.handle.net/10644/571

Correa Rubio, François. 2004. El sol del poder: simbología y política entre los muiscas del norte de los Andes. Bogotá: Unibiblos.

De la Cadena, Marisol. 2006. “Son los mestizos híbridos? Las políticas conceptuales de las identidades andinas”. Universitas Humanística 61: 51-84. https://revistas.javeriana.edu.co/ index.php/univhumanistica/article/view/2075

Díaz-Trechuelo, Lourdes, dir. 1991. La emigración andaluza a América, siglo XVII y XVIII. Sevilla: Consejería de Cultura.

Dueñas Vargas, Guiomar. 1997. Los hijos del pecado: ilegitimidad y vida familiar en la Santafé de Bogotá colonial. Bogotá: Editorial Universidad Nacional.

Eiras Roel, Antonio y Ofelia Rey Castelao. 1992. Los gallegos y América. Madrid: Mapfre.

Fisher, Andrew y Mathew O’Hara. 2009. “Introduction: racial identities and their interpreters in colonial Latin America”. En Imperial subjects: race and identity in colonial Latin America, editado por Andrew Fisher y Mathew O’Hara, 1-37. Durham: Duke University Press.

Garrido, Margarita. 2007. "Libres de todos los colores en Nueva Granada: identidad y obediencia antes de la Independencia”. En Cultura política en los Andes (1750-1950), editado por Cristóbal Aljovín de Losada y Nils Jacobsen, 245-266. Lima: IFEA; Fondo Editorial UNMSM.

Gutiérrez de Pineda, Virginia y Roberto Pineda Giraldo. 1999. Miscegenación y cultura en la Colombia colonial: 1750-1810. Bogotá: Colciencias; Universidad de los Andes. 
Hale, Charles R. 1996. "Mestizaje, hibridity, and the cultural politics of difference in postrevolutionary Latin America”. Journal of Latin American Anthropology 2 (1): 34-61. https:// doi.org/10.1525/jlca.1996.2.1.34

Herrera Ángel, Marta. 2001. "Las divisiones político-administrativas del Virreinato de la Nueva Granada a finales del periodo colonial”. Historia Crítica 22: 76-98. https://doi. org/10.7440/histcrit22.2001.04

-. 2002. Ordenar para controlar: ordenamiento espacial y control político en las llanuras del Caribe y en los Andes centrales neogranadinos, siglo XVIII. Bogotá: ICANH.

Herzog, Tamar. 2003. Defining nations: immigrants and citizens in early modern Spain and Spanish America. New Haven; Londres: Yale University Press.

Jaramillo Uribe, Jaime. 1965. "Mestizaje y diferenciación social en el Nuevo Reino de Granada en la segunda mitad del siglo XVIII". Anuario Colombiano de Historia Social y de la Cultura 3: 21-48. https://revistas.unal.edu.co/index.php/achsc/article/view/29674

LeGrand, Catherine. 1988. Colonización y protesta campesina 1850-1950. Bogotá: Universidad Nacional de Colombia.

Macías Hernández, Antonio M. 1994. "La emigración canaria a América. Estado de la cuestión”. En X Coloquio de Historia Canario-Americana (1992), t. 1, coordinado por Francisco Morales Padrón, 404-443. Las Palmas de Gran Canaria: Ediciones del Cabildo Insular de Gran Canaria.

Montaña Mestizo, Vladimir. 2003. Los cuchuqueros de antaño: sociedad, familia y mestizaje en un contexto rural de la Colonia: Suesca 1665-1722. Bogotá: Universidad Nacional de Colombia / Departamento de Antropología.

-. 2021. Mestizos de campo, mestizos de ciudad. Documento en preparación.

Mörner, Magnus. 1963. "Las comunidades indígenas y la legislación segregacionista en el Nuevo Reino de Granada”. Anuario de Historia Social y de la Cultura 1: 63-88. https://revistas.unal.edu.co/index.php/achsc/article/view/29622

- 1970. El colonato en la América meridional andina desde el siglo XVIII. Estocolmo: Instituto de Estudios Iberoamericanos.

-.1991. “Acerca de los motivos de los emigrantes españoles a Indias”. Huellas 33: 26-32. https:// www.uninorte.edu.co/documents/7399101/16475114/Huellas+No.+33.pdf/6a02c869-20c74f02-b97f-b046836f5bc9

-. 1995. "Spanish historians on Spanish migration to America during the colonial period". Latin America Research Review 30 (2): 251-267.

Nieto, Alejandro. 2002. "Desamortización ilustrada y desamortización liberal de la propiedad agraria”. En Historia de la propiedad en España: bienes comunales, pasado y presente, coordinado por Salustiano de Dios, Javier Infante Miguel-Motta, Ricardo Robledo Hernández y Eugenia Torijano Pérez, 257-290. Salamanca: Centro de Estudios Registrales.

Ots Capdequí, José María. 1952. "Sobre el régimen jurídico de la fundación de poblaciones, aprovechamientos de baldíos y explotación de la minería en el Nuevo Reino de Granada durante los primeros años del siglo XIX”. Revista del Colegio Mayor de Nuestra Señora del Rosario 47 (434): 179-196. 
-. 1959. España en América: el régimen de tierras. Ciudad de México: Fondo de Cultura Económica.

Pérez Picazo, María Teresa. 2003. "Proprieté collective et dessamortissement em Espagne”. En Les propriétés collectives face aux attaques libérales (1750-1914), dirigido por Marie-Danielle Damélas y Nadine Vivier, 197-217. Rennes: Presses Universitaires de Rennes.

Poloni-Simard, Jacques. 1999. "Redes y mestizaje. Propuestas para el análisis de la sociedad colonial”. En Lógica mestiza en América, editado por Guillaume Boccara y Sylvia Galindo, 113-137. Montevideo; Temuco: Universidad de la Frontera / Instituto de Estudios Indígenas.

Rappaport, Joanne. 2018. El mestizo evanescente: configuración de la diferencia en el Nuevo Reino de Granada. Bogotá: Universidad del Rosario.

Rodríguez, Pablo. 1997. Sentimientos y vida familiar en el Nuevo Reino de Granada. Bogotá: Ariel.

Rostand, Jean. (1958) 1995. "Les grandes problemes de la biologie”. En La science moderne de 1450 a 1800, editado por Rene Taton, 597-618. París: Puf.

Ruiz de Azúa y Martínez de Ezquerecocha, María Estibaliz. 1992. Vascongadas y América. Madrid: Mapfre.

Serje, Margarita. 1985. "El mito de la ausencia del Estado: la incorporación económica de las 'zonas de frontera' en Colombia”. Cahiers des Amériques Latines 71: 95-117. https://doi. org/10.4000/cal.2679

Sotomayor, María Lucía. 2004. Cofradías, caciques y mayordomos: reconstrucción social y reorganización política en los pueblos indios. Bogotá: ICANH.

Spalding, Karen. 1974. De indio a campesino. Lima: Instituto de Estudios Peruanos.

Tovar Pinzón, Hermes. 1988. Hacienda colonial y formación social. Barcelona: Sendai Editores. 